\title{
Drying Kinetic Analysis of Municipal Solid Waste Using Modified Page Model and Pattern Search Method
}

\author{
Junmeng Cai, $*, 1,2$ Yang Yang, ${ }^{2}$ Wenfei Cai, ${ }^{1}$ Tony Bridgwater ${ }^{2}$
}

${ }^{1}$ Biomass Energy Engineering Research Centre, Key Laboratory of Urban Agriculture (South) Ministry of Agriculture, School of Agriculture and Biology, Shanghai Jiao Tong University, 800 Dongchuan Road, Shanghai 200240, China

${ }^{2}$ Bioenergy Research Group, European Bioenergy Research Institute (EBRI), Aston University, Aston Triangle, Birmingham B4 7ET, UK

\begin{abstract}
This work studied the drying kinetics of the organic fractions of municipal solid waste (MSW) samples with different initial moisture contents and presented a new method for determination of drying kinetic parameters. A series of drying experiments at different temperatures were performed by using a thermogravimetric technique. Based on the modified Page drying model and the general pattern search method, a new drying kinetic method was developed using multiple isothermal drying curves simultaneously. The new method fitted the experimental data more accurately than the traditional method. Drying kinetic behaviors under extrapolated conditions were also predicted and validated. The new method indicated that the drying activation energies for the samples with initial moisture contents of $31.1 \%$ and $17.2 \%$ on wet basis were
\end{abstract}


25.97 and $24.73 \mathrm{~kJ} \mathrm{~mol}^{-1}$. These results are useful for drying process simulation and industrial dryer design. This new method can be also applied to determine the drying parameters of other materials with high reliability.

KEY WORDS: municipal solid waste (MSW); drying kinetics; pattern search method; drying activation energy; thermogravimetric technique

\section{GRAPHICAL ABSTRACT}

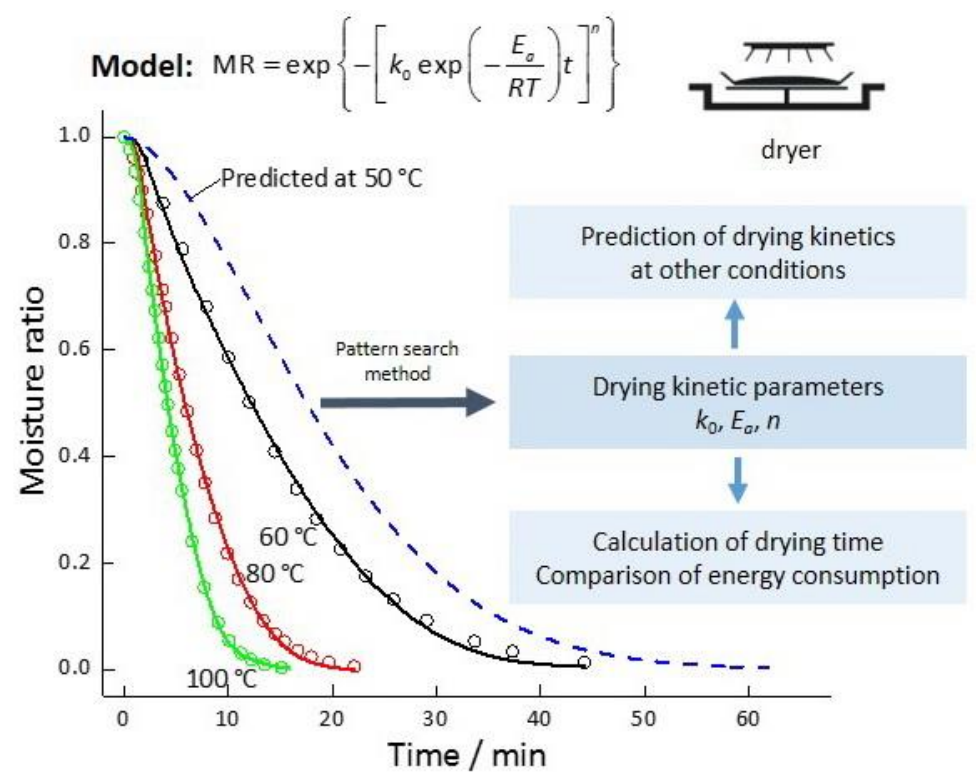

\section{INTRODUCTION}

Municipal solid waste (MSW) consists of everyday waste items discarded by the public that may include product packaging, grass clippings, furniture, clothing, bottles, food scraps, newspapers, appliances, paint, and batteries etc. ${ }^{1}$ Nowadays, the economic development and urbanization enable people to enjoy enriched material lives, but subsequently result in more solid waste generated. According to a recent report from World Bank, ${ }^{2}$ the current global annual MSW generation level will increase from about 
1.3 billion tons by 2011 to about 2.2 billion tons by 2025 .

Traditional MSW disposal methods, including landfilling and incineration, are unsustainable, as they use up land which can be otherwise used for arable farming and lead to loss of resources which could be recycled. ${ }^{3}$ In recent years, many countries and regions have implemented restrictions on landfilling and incineration of solid wastes. ${ }^{4}$ Those restrictions have proved to be effective to in encouraging higher recycling rates for MSW. ${ }^{4}$

Using MSW for energy application can reduce landfill and fossil fuels usage. Several technologies have been developed to process MSW for clean and economical energy generation. Depending on its composition and heating value, MSW can be used as a fuel for a variety of industrial purposes. ${ }^{5-8}$ Fast pyrolysis of the organic fractions of MSW has been attracting research attention for many years, as it offers an effective and sustainable way to produce a liquid - bio-oil - high efficiency. ${ }^{9}{ }^{10}$ Fast pyrolysis is a thermochemical decomposition process occurring at high temperatures (usually around $500{ }^{\circ} \mathrm{C}$ ) in the absence of oxygen. The organics in the raw material decompose into char, gas and pyrolysis vapor which can be condensed to form bio-oil. ${ }^{11}$ The water content of bio-oil is an essential parameter, as it affects the homogeneity, heating value and viscosity of bio-oil. Water in bio-oil results from the original moisture in the raw feedstock and the dehydration reactions occurring during pyrolysis. ${ }^{12}$ In fast pyrolysis for the production of bio-oil, the moisture content of the feedstock is generally reduced to less than $10 \mathrm{wt} . \%$ to prevent excessive water in the bio-oil product, which may cause phase separation and reduce oil quality. High water content in bio-oil leads to reduced heating value, increased ignition delay, decreased combustion rate and the propensity for phase separation. Therefore, a preliminary drying step for high moisture content MSW feedstock is necessary prior to fast pyrolysis, to reduce the amount of water in 
bio-oil as well as reduce energy consumption for the pyrolysis process. ${ }^{13}$

Analysis of the drying kinetics is fundamental for the optimization of drying conditions. The specific parameters (such as moisture diffusivity and drying activation energy) characterizing the drying process can be obtained and the drying rate can be empirically determined through drying kinetic analysis. ${ }^{14}$ The empirical relationships obtained are usually used in the programs that simulate the actual behavior of a dryer. 15 Investigations into the drying kinetics of solid wastes have been carried out extensively in the past decade. Wu et al. ${ }^{16}$ investigated the drying behaviors of four typical MSW components and obtained their effective moisture diffusion coefficients and drying activation energies. Chen et al. ${ }^{17}$ carried out the experimental drying study of MSW in a muffle furnace and pointed out that the diffusion coefficient of MSW was dependent on the initial moisture content and shrinkage effect. Chen et al. ${ }^{18}$ employed a thermogravimetric technique to study the drying kinetics of corn straw and wheat straw and found that their drying activation energies ranged from 10 to $30 \mathrm{~kJ} \mathrm{~mol}^{-1}$. Chen and $\mathrm{Ma}^{19}$ found that the drying activation energy for the MSW sample from Guangzhou, China was about $27 \mathrm{~kJ} \mathrm{~mol}^{-1}$.

In previous work, the effective moisture diffusivity and drying activation energy were determined by means of the traditional method which is based on the simplified solution of the Fick's second law of diffusion. However, some assumptions and simplifications are involved in the derivation of the traditional method, which leads to the conclusion that it cannot describe all three periods (i.e. preheating period, constant rate period and falling rate period) of the whole drying process. ${ }^{16}$ This will be discussed further in Section 3.

The drying kinetics of MSW with different initial moisture contents has been experimentally investigated at different isothermal drying temperatures. A new method 
has been developed for determination of the drying kinetic parameters by using multiple isothermal drying curves based on the modified Page kinetic model and the general pattern search method. The kinetic parameters were optimized by means of the generalized pattern search method which was implemented in MATLAB. The results from the new method were validated against experimental data and compared to those from the traditional method. The drying time was calculated from the kinetic parameters derived by the new method.

\section{MATERIAL AND EXPERIMENTS}

The MSW organic fraction sample was supplied by a UK commercial waste management company - Biffa Ltd.'s Leicester site in 2014. The sample supplied was the collected household waste after mechanical removal of the majority of the metals, glass, and plastics. The material was further shredded to small particles and processed with $2 \mathrm{~mm}$ rotary drum screen to improve the homogeneity of the sample. The product is referred to as the organic fraction of MSW and is the material used in this research.

The proximate and elemental analysis results of the received sample are shown in Table 1. The elemental analysis was carried out using Flash EA 1112 elemental analyzer (Thermo Fisher Scientific Inc., U.S.A.). Considering the inhomogeneity of the feedstock, the analysis results were repeated five times and the average results were reported. As shown in Table 1, the organic fractions of MSW feedstock contained high amount of moisture (31.1 wt.\%) and ash (36.3 wt.\%). 
Table 1. Proximate and elemental analysis results of as-received organic fraction sample

\begin{tabular}{|c|c|c|c|c|c|c|c|c|}
\hline \multicolumn{4}{|c|}{ Proximate analysis ${ }^{a}$} & \multicolumn{5}{|c|}{ Elemental analysis ${ }^{b}$} \\
\hline $\begin{array}{l}\text { Moisture } \\
\text { / wt. } \%\end{array}$ & $\begin{array}{l}\text { Ash / } \\
\text { wt.\% }\end{array}$ & $\begin{array}{l}\text { Volatile } \\
\text { / wt.\% }\end{array}$ & $\begin{array}{c}\text { Fixed } \\
\text { carbon }{ }^{\mathrm{c}} / \\
\text { wt.\% }\end{array}$ & $\begin{array}{c}\text { C / } \\
\text { wt. } \%\end{array}$ & $\begin{array}{c}\mathrm{H} / \\
\text { wt.\% }\end{array}$ & $\begin{array}{c}\mathrm{N} / \\
\text { wt. } \%\end{array}$ & $\begin{array}{c}\text { S / } \\
\text { wt. } \%\end{array}$ & $\begin{array}{l}\mathrm{O}^{\mathrm{c}} / \\
\text { wt. } \%\end{array}$ \\
\hline 31.1 & 36.3 & 15.2 & 17.4 & 43.6 & 6.2 & 1.7 & 1.5 & 47.0 \\
\hline \multicolumn{9}{|l|}{ a wet basis } \\
\hline \multicolumn{9}{|c|}{ dry-ash-free basis } \\
\hline
\end{tabular}

In order to investigate the drying kinetics of the samples with different initial moisture contents, the sample received was dried in a muffle oven at $60{ }^{\circ} \mathrm{C}$ for about an hour to reduce its initial moisture content from $31.1 \%$ to $17.2 \%$.

The isothermal drying experiments of the samples were conducted in an electronic moisture analyzer (Sartorius MA35, Sartorius Weighting Technology GmbH, Germany). The moisture analyzer employs a thermogravimetric technique to provide determination of water loss of materials. It consists of a heating unit, a weighing system, and a display and control unit. A diagram of the moisture analyzer is shown in Figure 1. Circular aluminum pans of $90 \mathrm{~mm}$ diameter and $10 \mathrm{~mm}$ height were used in the drying experiments. A thin layer of sample was spread evenly in the pan before drying. The reason for selecting the current moisture analyzer is due to the consideration of the nature of inhomogeneity of the feedstock and real industrial drying scenario. Comparing to previous work ${ }^{17,18}$ carried out in thermogravimetric analyzers which employed a few milligram of material, the moisture analyzer can work on over $10 \mathrm{~g}$ of sample and therefore reduce the system error. A series of experiments were carried out under various controlled temperatures, initial moisture contents, and drying time periods by using the moisture analyzer. The drying experimental conditions are 
summarized in Table 2. Each experimental condition was done in triplicate and average results reported.

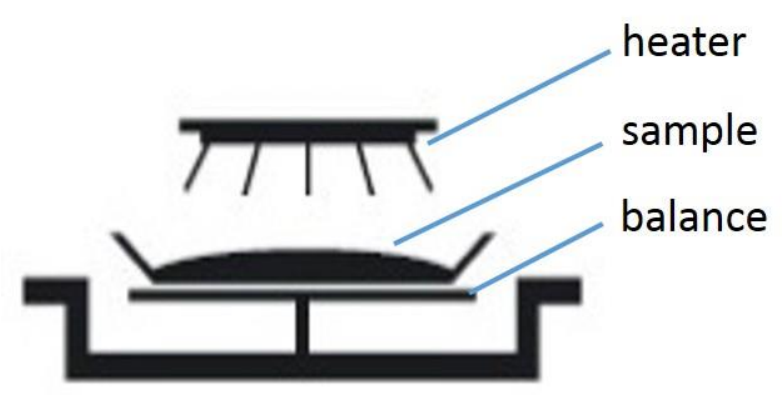

Figure 1. Schematic diagram of moisture analyzer

Table 2. Drying experimental conditions of samples

\begin{tabular}{cccc}
\hline Run & Sample's initial moisture content $/ \%$ & Temperature $/{ }^{\circ} \mathrm{C}$ & Time $/$ min \\
\hline 1 & 31.1 & 60 & 60 \\
2 & & 80 & 45 \\
3 & 17.2 & 100 & 30 \\
\hline 4 & & 60 & 60 \\
5 & & 80 & 45 \\
6 & 100 & 30 \\
\hline
\end{tabular}

\section{TRADITIONAL DRYING KINETIC METHOD}

As described earlier, the commonly used traditional method for determination of the effective moisture diffusivity and activation energy was developed based on Fick's second law of diffusion: ${ }^{19}$

$$
\frac{\mathrm{dMR}}{\mathrm{d} t}=D_{e f f} \frac{\mathrm{d}^{2} \mathrm{MR}}{\mathrm{d} x^{2}}
$$

where $t$ is time (s), $D_{\text {eff }}$ is the effective moisture diffusivity $\left(\mathrm{m}^{2} \mathrm{~s}^{-1}\right), x$ is the spatial 
dimension (m), and MR is the moisture ratio. The moisture ratio is a key parameter for drying study. It is defined as the ratio of the residual moisture $\left(w_{t}-w_{e}\right)$ to the total available moisture $\left(w_{0}-w_{e}\right)$ that can be removed at any particular time $t$ during drying and is expressed as:

$$
\mathrm{MR}=\frac{w_{t}-w_{e}}{w_{0}-w_{e}}
$$

where $w_{t}$ is the moisture content at any particular time $t, w_{0}$ is the initial moisture content, and $w_{e}$ is the equilibrium moisture content (at which point, the material stopped losing moisture).

Concerning the moisture diffusivity, the relationship between $D_{\text {eff }}$ and $T$ (the temperature, K) can be described by the Arrhenius law:

$$
D_{\text {eff }}=D_{0} \exp \left(-\frac{E_{a}}{R T}\right)
$$

where $D_{0}$ is the Arrhenius preexponential factor $\left(\mathrm{m}^{2} \mathrm{~s}^{-1}\right), E_{a}$ is the activation energy $(\mathrm{J}$ $\left.\mathrm{mol}^{-1}\right)$, and $R$ is the universal gas constant $\left(8.3145 \mathrm{~J} \mathrm{~mol}^{-1} \mathrm{~K}^{-1}\right)$.

When internal mass transfer as the controlling mechanism and one-dimensional transport in an infinite slab is assumed, the mathematical solution of Equation (1) can be expressed by the following equation: ${ }^{19}$

$$
\mathrm{MR}=\frac{8}{\pi^{2}} \sum_{i=0}^{\infty} \frac{1}{(2 i+1)^{2}} \exp \left[\frac{-\pi^{2}(2 i+1)^{2}}{4 L_{0}^{2}} D_{e f f} t\right]
$$

where $L_{0}$ is the half-thickness of the slab (m).

For sufficiently long drying time, the terms in the general series solution (4) may be approximated by the first term of the series:

$$
\mathrm{MR}=\frac{8}{\pi^{2}} \exp \left[\frac{-\pi^{2}}{4 L_{0}^{2}} D_{\text {eff }} t\right]
$$

Applying natural logarithm to Equation (5) 


$$
\ln (\mathrm{MR})=\ln \left(\frac{8}{\pi^{2}}\right)-\frac{\pi^{2}}{4 L_{0}{ }^{2}} D_{e f f} t
$$

It can be easily obtained from Equation (6) that $\ln (\mathrm{MR})$ and $t$ is in linear relation and that $D_{\text {eff }}$ can be calculated from the slope.

Rearrange Equation (3) to calculate $E_{a}$

$$
\ln \left(D_{\text {eff }}\right)=\ln \left(D_{0}\right)-\frac{E_{a}}{R T}
$$

Equation (7) indicates that the relationship between the $\ln \left(D_{\text {eff }}\right)$ values obtained at different drying temperatures and $-1 / T$ is linear with $E_{a} / R$ being the slope.

However, in most cases, the $\ln (\mathrm{MR})$ - $t$ curves for drying of materials have a concave form. ${ }^{20}$ The reason for this is the assumption of the invariability of the effective moisture diffusion during drying while deriving Equation (6). Nevertheless the linear relationship expressed in Equation (6) is only suitable to describe the falling rate period of the drying process, which is the only exponential decay stage among the isothermal drying curve, according to the derivative form of Equation (5): $\frac{\mathrm{dMR}}{\mathrm{d} t}=-\frac{2 D_{e f f}}{L_{0}^{2}} \exp \left[\frac{-\pi^{2}}{4 L_{0}^{2}} D_{\text {eff }} t\right]$. In comparison to an experimental drying curve, Equation (5) would tend to over-predict the preheating period and under-predict the constant drying rate period of the drying process when it would be used to fit the isothermal drying curve of a drying process. ${ }^{16}$ When the drying activation energy is determined from the traditional method, a sequence of linear regression calculations is made, and errors may accumulate.

\section{NEW DRYING KINETIC METHOD}

Several different empirical drying models have been proposed to address the 
limitation of the traditional method. ${ }^{20}$ Of those drying models, the modified Page model, as proposed by White et al., ${ }^{24}$ is one of the most widely used models due to its high accuracy and simplicity. ${ }^{16}$ Thus, the new method developed in the present work is based on this model:

$$
\operatorname{MR}=\exp \left[-(k t)^{n}\right]
$$

where $k$ is the pseudo moisture diffusivity. ${ }^{21}$ According to Dadal1 et al., ${ }^{26}$ the following relationship between $k$ and $D_{\text {eff }}$ exists:

$$
k=\lambda D_{\text {eff }}
$$

where $\lambda$ is an empirical constant.

According to Equations (3), (8) and (9), the comprehensive drying kinetic model incorporating all kinetic parameters can be derived:

$$
\mathrm{MR}=\exp \left\{-\left[\lambda D_{0} \exp \left(-\frac{E_{a}}{R T}\right) t\right]^{n}\right\}=\exp \left\{-\left[k_{0} \exp \left(-\frac{E_{a}}{R T}\right) t\right]^{n}\right\}
$$

where $k_{0}=\lambda D_{0}$ is the pseudo preexponential factor.

The drying kinetic behaviors at different temperatures can be described by the same set of parameters $\left(k_{0}, E_{a}\right.$, and $\left.n\right)$ in Equation (10). In the new method, by using experimental data in the form of multiple isothermal drying curves simultaneously, all drying kinetic parameters can be determined by minimization of the following objective function:

$$
\begin{aligned}
\text { O.F. } & =\sum_{i=1}^{m} \sum_{j=1}^{n_{d i}}\left(\mathrm{MR}_{c a l, i j}-\mathrm{MR}_{\text {exp }, i j}\right)^{2} \\
& =\sum_{i=1}^{m} \sum_{j=1}^{n_{d i}}\left\{\exp \left\{-\left[k_{0} \exp \left(-\frac{E_{a}}{R T_{i}}\right) t_{i j}\right]^{n}\right\}-\mathrm{MR}_{\text {exp }, i j}\right\}^{2}
\end{aligned}
$$

where the subscripts exp and cal represent the experimental values and the values 
calculated by the model, respectively, $n_{d i}$ is the number of data points of the isothermal drying at $T_{i}, m$ is the number of drying temperatures, and the subscript $i j$ represents the value related on the $j$ th data point of the isothermal drying curve at $T_{i}$.

In order to determine the $k_{0}, E_{a}$, and $n$ values by minimizing the objective function (11), a derivative-free optimization method should be used, as the objective function (11) has no explicit expression and it is difficult to obtain its derivative information. In this work, the generalized pattern search method was chosen, as it does not require any information about the derivative of the objective function. It proceeds by computing a sequence of points involving exploratory search and pattern move. The flow chart of the generalized pattern search method is depicted in Figure 2.

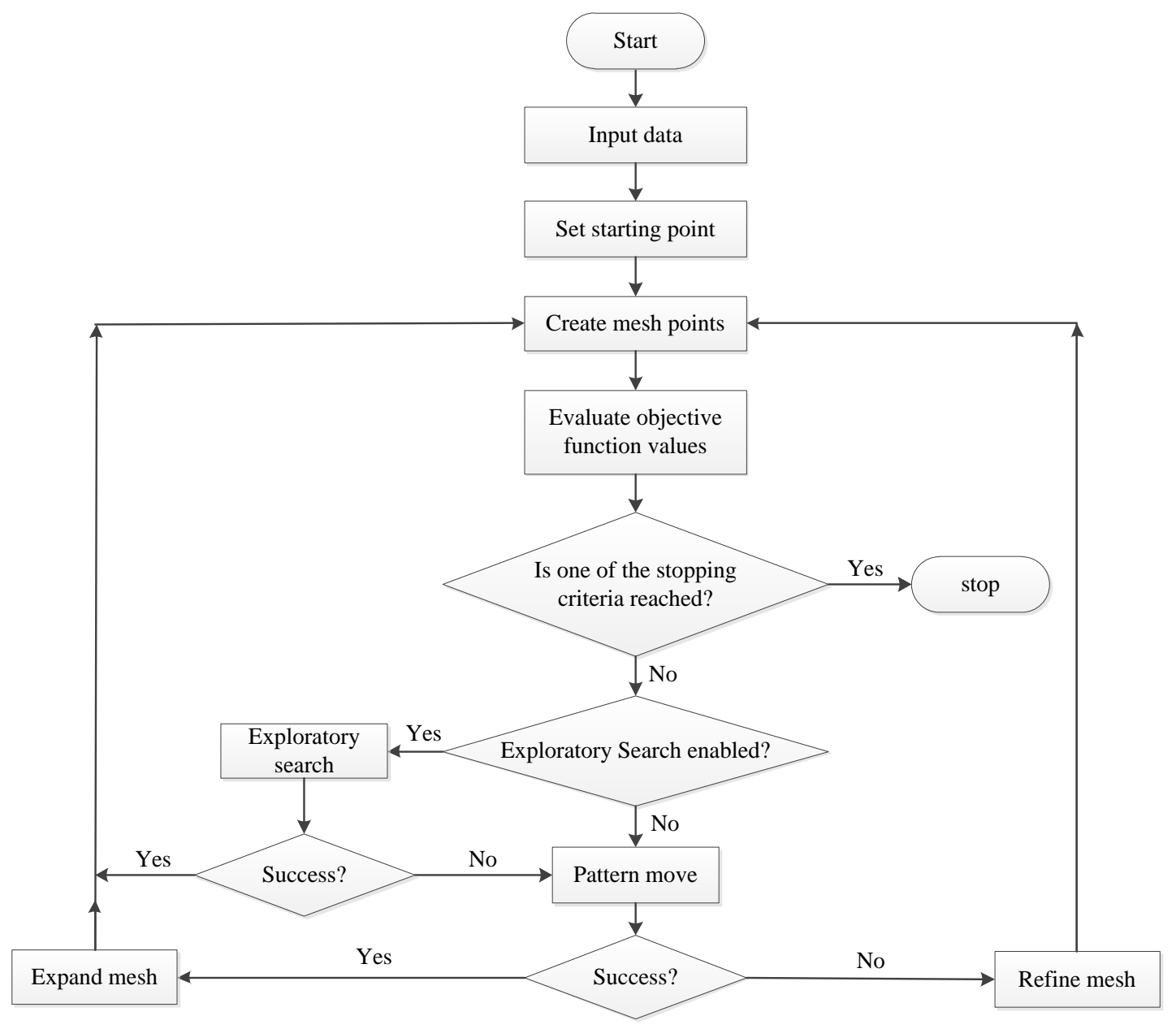

Figure 2. Flow chart of generalized pattern search method 
The objective function (11) was coded in the MATLAB environment (shown in Appendix A) and the implementation of the generalized pattern search method was carried out by means of MATLAB Optimization Toolbox.

Two statistical measures were adopted to evaluate the goodness-of-fit of each method for each isothermal drying kinetic curve, i.e. the coefficient of determination $\left(\mathrm{R}^{2}\right)$ and root mean square error (RMSE). They are defined bellows:

$$
\begin{aligned}
\mathrm{R}_{i}^{2} & =\sum_{j=1}^{n_{i}} \frac{\left(\mathrm{MR}_{c a l, i j}-\overline{\mathrm{MR}_{\text {exp }, i}}\right)^{2}}{\left(\mathrm{MR}_{\text {exp }, i j}-\overline{\mathrm{MR}_{\text {exp }, i}}\right)^{2}} \\
\mathrm{RMSE}_{i} & =\sqrt{\frac{1}{n_{i}} \sum_{j=1}^{n_{i}}\left(\mathrm{MR}_{c a l, i j}-\mathrm{MR}_{\text {exp }, i j}\right)^{2}}
\end{aligned}
$$

where $\overline{\mathrm{MR}_{\text {exp }, i}}$ represents the mean value of the experimental moisture ratio for the drying experimental curve at $T_{i}$. The $\mathrm{R}^{2}$ is interpreted as the proportion of the variance in the dependent variable that is predictable from the independent variable and the RMSE represents the standard deviation of the differences between experimental and predicted. The $\mathrm{R}^{2}$ value ranges from 0 to 1 , with closer to 1 representing a better fitting, and the lower the RMSE value, the better will be the goodness-of-fit.

\section{RESULTS AND DISCUSSION}

Linear regressions of $\ln (\mathrm{MR})$ versus $t$ for the samples at different temperatures have been performed and the results are presented in Figure 3. The $\ln (\mathrm{MR})$ versus $t$ plot under each condition shows a concave shape and deviates from the linear line. The $D_{\text {eff }}$ value at each drying temperature was obtained from the slope of the corresponding linear fit according to Equation (6) despite poor goodness-of-fit. The relationship 
between $\ln \left(D_{\text {eff }}\right)$ and $-1 / T$ was plotted and the corresponding linear regression was performed, as shown in Figure 4. It can be seen that the linearity of the relationship between $\ln \left(D_{\text {eff }}\right)$ and $-1 / T$ was not good. According to the traditional method, the activation energies for drying of the samples with initial moisture contents of $31.1 \%$ and $17.2 \%$ on wet basis were calculated to be $28.9 \pm 8.1$ and $25.9 \pm 7.4 \mathrm{~kJ} \mathrm{~mol}^{-1}$, respectively. The standard deviations (over $28.0 \%$ of drying activation energy mean value) were relatively large, which indicated that the activation energies obtained by the traditional method contained considerable errors.
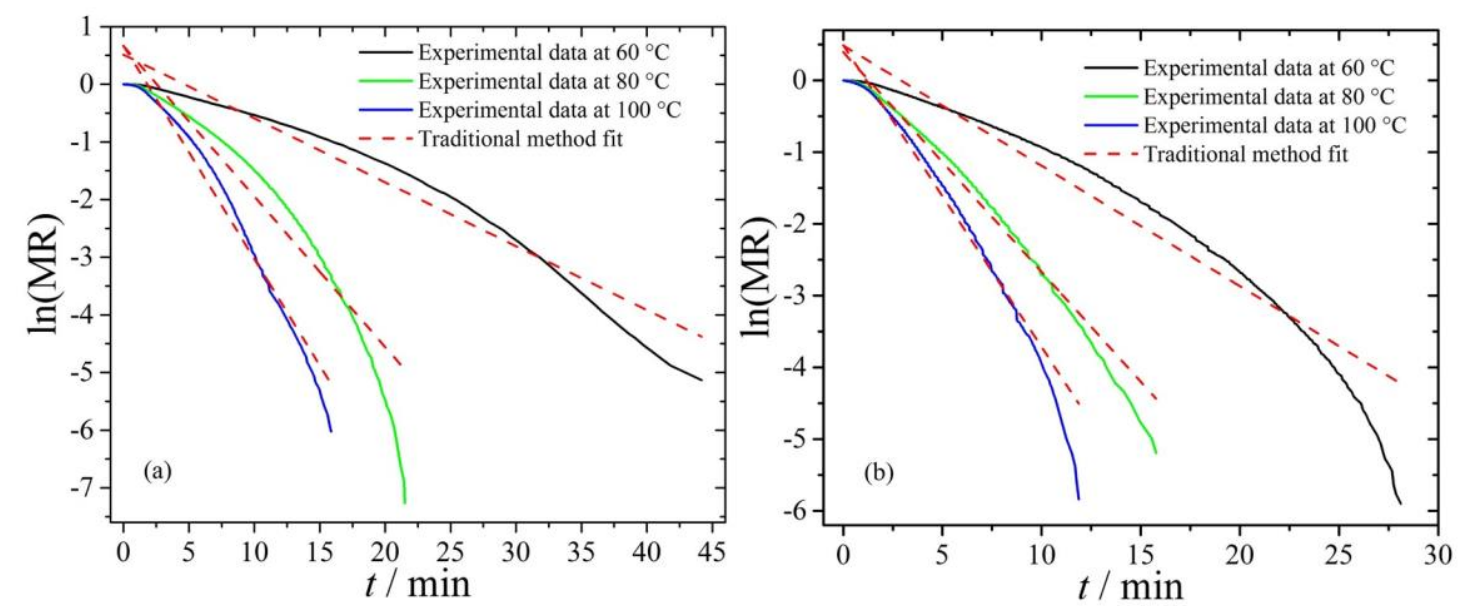

Figure 3. Processing of $\ln (\mathrm{MR})$ versus $t$ curves by traditional method for drying of MSW samples with initial moisture contents of (a) $31.1 \%$ and (b) $17.2 \%$ 

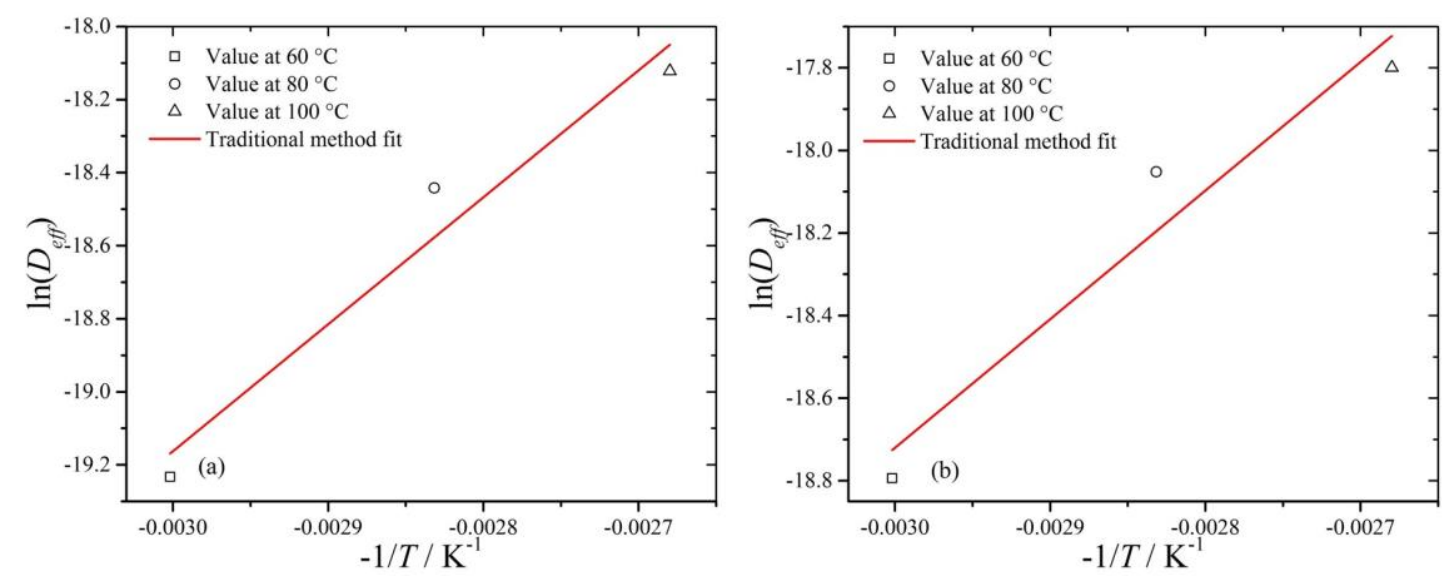

Figure 4. Processing of $\ln \left(D_{\text {eff }}\right)$ versus $-1 / T$ curves for drying of MSW samples with initial moisture contents of (a) $31.1 \%$ and (b) $17.2 \%$ (in the figures, $D_{\text {eff }}$ is expressed in $\mathrm{m}^{2} \mathrm{~s}^{-1}$ )

The same experimental data sets were processed by means of the new method. The convergence of optimal solutions by using the generalized pattern search method was shown in Figure 5. The drying kinetic parameter values for drying of MSW samples with initial moisture contents of $31.1 \%$ and $17.2 \%$ on wet basis by means of the new method are shown in Table 3. Table 3 also presents the corresponding statistical measures obtained from the traditional and new methods. From Table 3, the RMSE values from the new method are at least 3.1 times less than those from the traditional method, and the $\mathrm{R}^{2}$ values from the new method are greater than 0.998 (which implies a nearly perfect agreement with the experimental data), while the maximum $\mathrm{R}^{2}$ value from the traditional method is 0.978 . These results indicated that, as shown in Figure 6, the new method gave a better description of the drying kinetics during the entire drying processes of the samples than the traditional method did. 

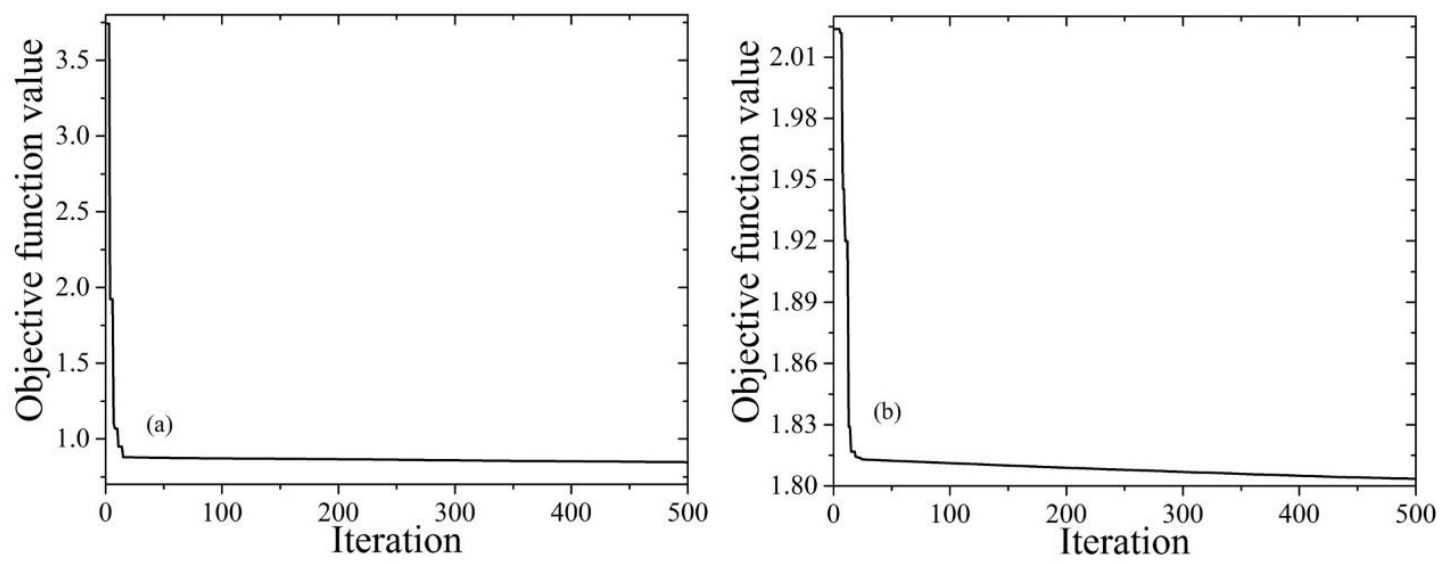

Figure 5. Convergence of generalized pattern search method for processing of drying experimental data of the organic fractions of MSW samples with initial moisture contents of (a) $31.1 \%$ and (b) $17.2 \%$ 

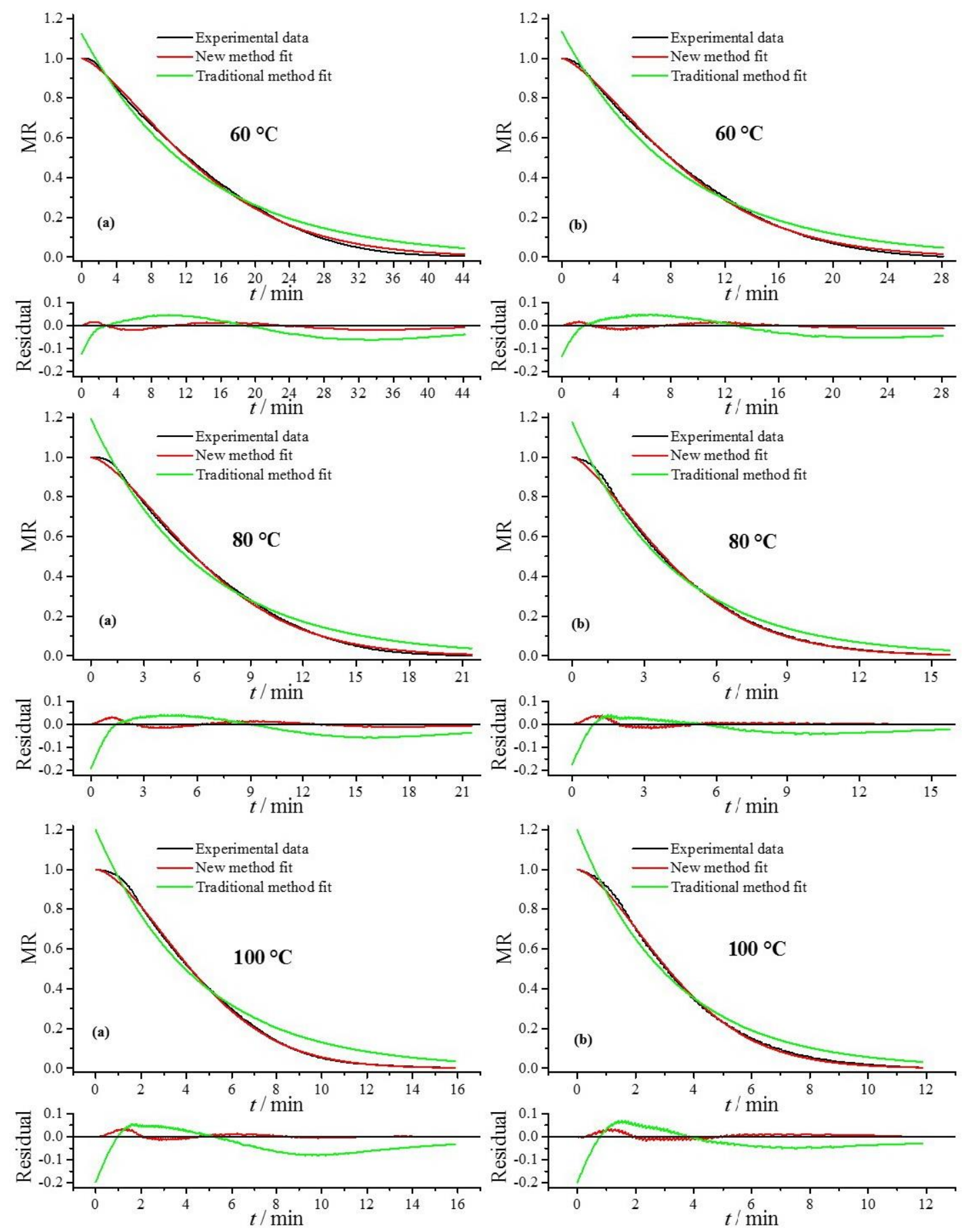

Figure 6. Experimental and predicted MR values by traditional and new methods for drying of MSW samples with initial moisture contents of (a) $31.1 \%$ and (b) $17.2 \%$ 
Table 3. Drying kinetic parameters and statistical analysis results from new and traditional methods

\begin{tabular}{|c|c|c|c|c|c|c|c|c|}
\hline \multirow{2}{*}{$\begin{array}{l}\text { Sample's initial moisture content } \\
\qquad \mathrm{a}\end{array}$} & \multirow{2}{*}{$\begin{array}{l}\text { Drying temperature } \\
\qquad /{ }^{\circ} \mathrm{C}\end{array}$} & \multicolumn{3}{|c|}{ Kinetic parameters from new method } & \multicolumn{2}{|c|}{ New method } & \multicolumn{2}{|c|}{ Traditional method } \\
\hline & & $\ln \left(k_{0}\right) /\left(k_{0}\right.$ is expressed in $\left.\mathrm{s}^{-1}\right)$ & $E_{a} / \mathrm{kJ} \mathrm{mol}^{-1}$ & $n$ & $\mathrm{R}^{2}$ & RMSE & $\mathrm{R}^{2}$ & RMSE \\
\hline \multirow[t]{3}{*}{31.1} & 60 & 2.649 & 25.97 & 1.531 & 0.9986 & $1.1914 \times 10^{-2}$ & 0.9730 & $5.1333 \times 10^{-2}$ \\
\hline & 80 & & & & 0.9987 & $1.2384 \times 10^{-2}$ & 0.9758 & $5.0563 \times 10^{-2}$ \\
\hline & 100 & & & & 0.9989 & $1.0940 \times 10^{-2}$ & 0.9648 & $6.1732 \times 10^{-2}$ \\
\hline \multirow[t]{3}{*}{17.2} & 60 & 2.572 & 24.73 & 1.428 & 0.9992 & $9.6486 \times 10^{-3}$ & 0.9757 & $5.0603 \times 10^{-2}$ \\
\hline & 80 & & & & 0.9982 & $1.2713 \times 10^{-2}$ & 0.9781 & $5.3048 \times 10^{-2}$ \\
\hline & 100 & & & & 0.9986 & $1.1575 \times 10^{-2}$ & 0.9672 & $6.7406 \times 10^{-2}$ \\
\hline
\end{tabular}


To validate the drying kinetic parameters obtained at 60,80 and $100{ }^{\circ} \mathrm{C}$ for other temperatures, the obtained $k_{0}, E_{a}$ and $n$ included in Table 3 were used to predict the drying behavior at $70{ }^{\circ} \mathrm{C}$ for the samples. The calculated MR curves from the new method were compared with the experimental data for validation, as shown in Figure 7. The $\mathrm{R}^{2}$ and RMSE were 0.9995 and $1.361 \times 10^{-2}$ for the sample with initial moisture content of $31.1 \%$, and 0.9990 and $1.237 \times 10^{-2}$ for the sample with initial moisture content of $17.2 \%$, respectively. The results showed high agreement between the predicted and experimental data and hence provided a validation for the new method. This suggests that the drying kinetic parameters obtained from the experimental data at 60,80 and $100{ }^{\circ} \mathrm{C}$ by the new method can be used to predict the drying kinetic behavior under extrapolated conditions.
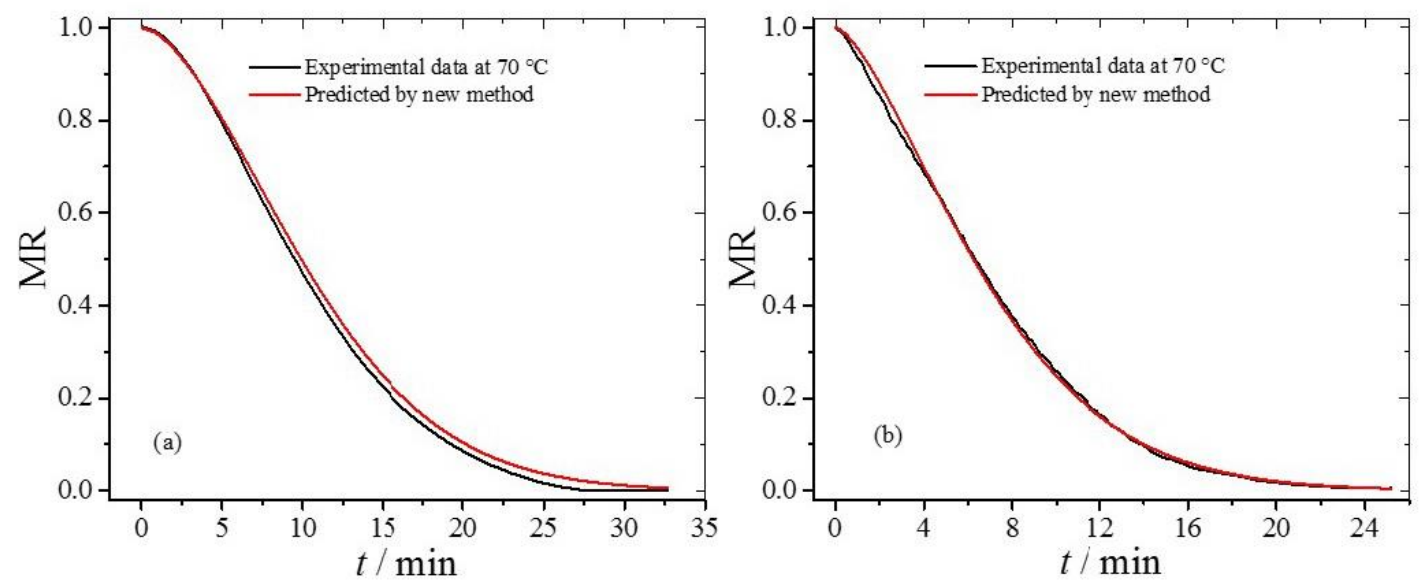

Figure 7. Validation of optimized parameters obtained at 60,80 and $100{ }^{\circ} \mathrm{C}$ usability for drying of MSW samples with initial moisture contents of (a) $31.1 \%$ and (b) $17.2 \%$ at $70{ }^{\circ} \mathrm{C}$

Based on the kinetic parameters calculated from the new method, the drying time, $t_{d}$, of the samples at various drying temperatures can be accurately obtained. In the present work, the $t_{d}$ value is considered as the period of time that the MR value is 
reduced from 1 to 0.1 . The raw materials with $0.1 \mathrm{MR}$ is considered as a satisfactory moisture content for pyrolysis treatment, as too dry feedstock can result in highly viscous bio-oils. ${ }^{22} \mathrm{~A}$ drying temperature range of 50 to $100{ }^{\circ} \mathrm{C}$ is selected for calculation of $t_{d}$. This is due to the fact that in industrial drying processes, drying temperature usually exceeds $50{ }^{\circ} \mathrm{C}$ and above $110{ }^{\circ} \mathrm{C}$ the organic fractions of MSW may begin to decompose. ${ }^{23}$ The $t_{d}$ values at various temperatures for the samples with initial moisture contents of $31.1 \%$ and $17.2 \%$ were calculated and listed in Table 4. From Table 4, it can be deduced that an increase in drying temperature can speed up the drying process and hence reduce the drying time; and also that the drying time of the sample with an initial moisture content of $17.2 \%$ is much shorter than that of the sample with initial moisture content of $31.1 \%$ at a same drying temperature.

Table 4. Drying time required at various drying temperatures

\begin{tabular}{|c|c|c|}
\hline Sample initial moisture content ${ }^{\mathrm{a}} / \%$ & Drying temperature $/{ }^{\circ} \mathrm{C}$ & $t_{d} / \min$ \\
\hline \multirow[t]{6}{*}{31.1} & 50 & 35.80 \\
\hline & 60 & 26.63 \\
\hline & 70 & 20.17 \\
\hline & 80 & 15.52 \\
\hline & 90 & 12.10 \\
\hline & 100 & 9.57 \\
\hline \multirow[t]{6}{*}{17.2} & 50 & 23.87 \\
\hline & 60 & 18.10 \\
\hline & 70 & 13.98 \\
\hline & 80 & 10.95 \\
\hline & 90 & 8.68 \\
\hline & 100 & 6.98 \\
\hline
\end{tabular}

\footnotetext{
${ }^{\mathrm{a}}$ wet basis
} 


\section{APPLICATION}

Figure 8 is a schematic flow chart for the overall process design of dryers. ${ }^{24}$ In general, dryer design calculations require mass and heat transfer information as well as drying kinetics information. The optimal design parameters for a dryer should meet the requirements of thermal and mass transfer efficiency and drying kinetics. ${ }^{25}$

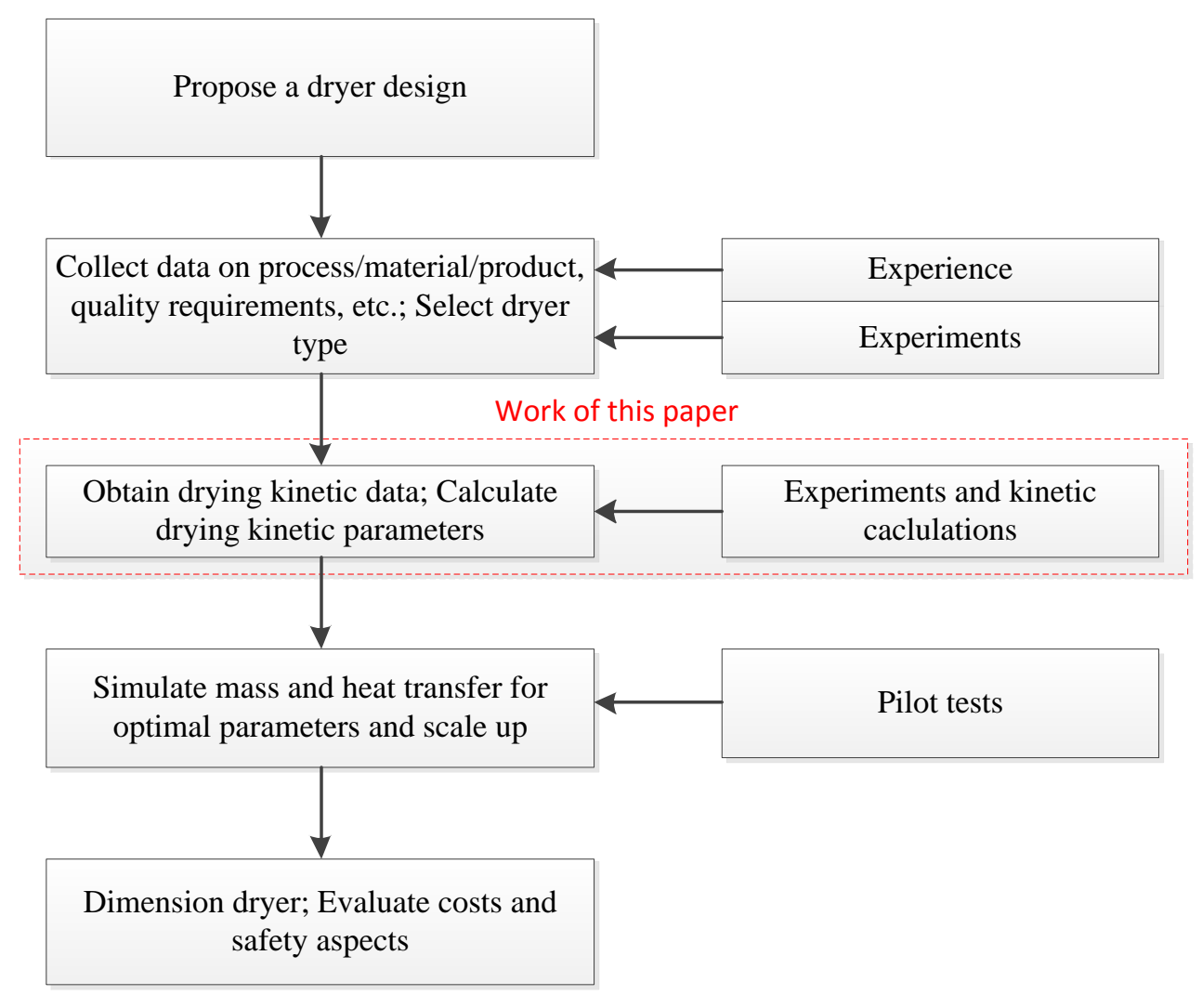

Figure 8. Flow chart for process design of dryer

This work primarily contributes to the third step in Figure 8. Usually, the drying kinetic data is obtained under constant drying conditions. However, in actual dryers, the drying material is usually exposed to varying conditions (e.g. different temperatures). Thus, it is necessary to develop a drying kinetic model to interpolate or extrapolate highly reliable additional drying data over a range of drying conditions based on limited experimental investigation. 
To determine the dryer geometries and dimensions and optimize drying conditions, it is necessary to do computational simulations of heat and mass transfer for the proposed dryer, where the corresponding kinetic model is required. ${ }^{25}$

\section{CONCLUSIONS}

1) Based on the modified Page drying model and the general pattern search method, a new method which can enable us to obtain the parameters by simultaneously using multiple isothermal drying curves was developed.

2) The new method presented in this work can satisfactorily describe the whole drying process and provided a better fitting to the experimental data of MSW drying kinetics than the traditional drying kinetic method.

3) The drying activation energies for drying of the samples with initial moisture contents of $31.1 \%$ and $17.2 \%$ on wet basis were determined to be 25.97 and 24.73 $\mathrm{kJ} \mathrm{mol}^{-1}$, which are lower than those obtained by the traditional method of 28.9 and $25.9 \mathrm{~kJ} \mathrm{~mol}^{-1}$, respectively.

4) The higher drying temperature can accelerate the evaporation of water in MSW thus reducing the drying time. At the same drying temperature, the drying time required is shorter for the MSW sample with lower initial water content.

\section{Appendix A. MATLAB code for the objective function (ObjectiveFunction.m):}

function errsum=ObjectiveFunction $(\mathrm{X})$

$\% \mathrm{X}$ is the vector of drying kinetic parameters $\%$

$\mathrm{k} 0=\mathrm{X}(1)$;

$\mathrm{Ea}=\mathrm{X}(2)$; 
$\mathrm{n}=\mathrm{X}(3)$

load data.mat;

$\%$ Load experimental data at 60,80 and $100{ }^{\circ} \mathrm{C} \%$

\% Including t1, MR1, t2, MR2, t3, and MR3 \%

for $\mathrm{j}=1$ :length(MR1)

MRcal1(j) $=\exp \left(-\left(\exp \left(k 0-10000 * \mathrm{Ea} /\left(8.3145^{*}(60+273.15)\right)\right)^{*} \mathrm{t} 1(\mathrm{j})\right)^{\wedge} \mathrm{n}\right)$;

$\operatorname{err1}(\mathrm{j})=(\operatorname{MR} 1(\mathrm{j})-\mathrm{MRcal1}(\mathrm{j}))^{\wedge} 2$;

end

errsum $1=\operatorname{sum}(\operatorname{err} 1)$

for $\mathrm{j}=1$ :length(MR2)

$\operatorname{MRcal2}(\mathrm{j})=\exp (-(\exp (\mathrm{k} 0-10000 * \mathrm{Ea} /(8.3145 *(80+273.15))) * \mathrm{t} 2(\mathrm{j})) \wedge \mathrm{n})$;

$\operatorname{err} 2(\mathrm{j})=(\operatorname{MR} 2(\mathrm{j})-\operatorname{MRcal} 2(\mathrm{j}))^{\wedge} 2$;

end

errsum2=sum(err2);

for $\mathrm{j}=1$ :length(MR3)

$\operatorname{MRcal3}(\mathrm{j})=\exp \left(-\left(\exp \left(\mathrm{k} 0-10000^{*} \mathrm{Ea} /\left(8.3145^{*}(100+273.15)\right)\right)^{*} \mathrm{t} 3(\mathrm{j})\right)^{\wedge} \mathrm{n}\right)$;

$\operatorname{err} 3(\mathrm{j})=(\operatorname{MR} 3(\mathrm{j})-\operatorname{MRcal} 3(\mathrm{j}))^{\wedge} 2$;

end

errsum3=sum(err3);

errsum=errsum $1+$ errsum $2+$ errsum 3 ;

\section{AUTHOR INFORMATION}

Corresponding author

* Tel.: +8621 34206624. Fax: +8621 34205744. E-mail: jmcai@ @jtu.edu.cn.

Notes 
The authors declare no competing financial interest.

\title{
ACKNOWLEDGEMENTS
}

Junmeng Cai and Wenfei Cai would like to acknowledge the financial support from the IRSES ECOFUEL programme (FP7-PEOPLE-2009-IRSES Grant 246772). Yang Yang would like to acknowledge the support from the EPSRC Supergen Bioenergy Challenge "PyroAD” Project (EP/K036793/1).

\section{NOMENCLATURES AND SUBSCRIPTS}

\author{
Nomenclatures \\ MR Moisture ratio \\ MSW Municipal Solid Waste \\ O.F. Objective function \\ RMSE Root mean square error \\ $D_{0} \quad$ Arrhenius preexponential factor \\ $D_{\text {eff }} \quad$ Effective moisture diffusivity \\ $E_{a} \quad$ Drying activation energy \\ $k \quad$ Pseudo moisture diffusivity \\ $k_{0} \quad$ Pseudo preexponential factor \\ $L_{0} \quad$ Half-thickness of the slab \\ $m \quad$ Number of drying temperatures \\ $n \quad$ Exponent \\ $n_{d} \quad$ Number of data points \\ $R \quad$ Universal gas constant \\ $\mathrm{R}^{2} \quad$ Coefficient of determination \\ $t \quad$ Time \\ $T \quad$ Temperature \\ $w_{0} \quad$ Initial moisture content \\ $w_{e} \quad$ Equilibrium moisture content
}




$\begin{array}{ll}w_{t} & \text { Moisture content at any particular time } \\ x & \text { Spatial dimension } \\ \lambda & \text { Empirical constant }\end{array}$

\section{Subscripts}

$\begin{array}{ll}\text { cal } & \text { Calculated data } \\ \text { exp } & \text { Experimental data } \\ i & \text { The } i \text { th temperature } \\ j & \text { The } j \text { th data point }\end{array}$

\section{REFERENCES}

1. Basso, D.; Weiss-Hortala, E.; Patuzzi, F.; Castello, D.; Baratieri, M.; Fiori, L., Hydrothermal carbonization of off-specification compost: A byproduct of the organic municipal solid waste treatment. Bioresource Technology 2015, 182, (0), 217-224.

2. Hoornweg, D.; Bhada-Tata, P. What a waste: A global review of solid waste management; World Bank Report: Washington, DC 20433, USA, 2012.

3. Jayasinghe, P. A.; Hettiaratchi, J. P. A.; Mehrotra, A. K.; Kumar, S., Reaction mechanisms and rate constants of waste degradation in landfill bioreactor systems with enzymatic-enhancement. Bioresource Technology 2014, 162, (0), 279-282.

4. Chandrappa, R.; Brown, J., Solid Waste Management: Principles and Practice. Springer Berlin Heidelberg: 2012.

5. Chen, D.; Yin, L.; Wang, H.; He, P., Pyrolysis technologies for municipal solid waste: A review. Waste Management 2014, 34, (12), 2466-2486.

6. Yuan, X.; Wen, B.; Ma, X.; Zhu, W.; Wang, X.; Chen, S.; Cui, Z., Enhancing the anaerobic digestion of lignocellulose of municipal solid waste using a microbial pretreatment method. Bioresource Technology 2014, 154, (0), 1-9.

7. Tawfik, A.; El-Qelish, M., Key factors affecting on bio-hydrogen production from 
co-digestion of organic fraction of municipal solid waste and kitchen wastewater. Bioresource Technology 2014, 168, (0), 106-111.

8. Pandey, D. S.; Pan, I.; Das, S.; Leahy, J. J.; Kwapinski, W., Multi-gene genetic programming based predictive models for municipal solid waste gasification in a fluidized bed gasifier. Bioresource Technology 2015, 179, (0), 524-533.

9. Yang, Y.; Brammer, J. G.; Mahmood, A. S. N.; Hornung, A., Intermediate pyrolysis of biomass energy pellets for producing sustainable liquid, gaseous and solid fuels. Bioresource Technology 2014, 169, (0), 794-799.

10. Bridgwater, A. V., Review of fast pyrolysis of biomass and product upgrading. Biomass and Bioenergy 2012, 38, 68-94.

11. Banks, S. W.; Nowakowski, D. J.; Bridgwater, A. V., Fast pyrolysis processing of surfactant washed Miscanthus. Fuel Processing Technology 2014, 128, (0), 94-103.

12. Czernik, S.; Bridgwater, A. V., Overview of applications of biomass fast pyrolysis oil. Energy \& Fuels 2004, 18, (2), 590-598.

13. Perazzini, H.; Freire, F. B.; Freire, F. B.; Freire, J. T., Thermal treatment of solid wastes using drying technologies: A Review. Drying Technology 2015, DIO: $10.1080 / 07373937.2014 .995803$

14. Chen, D.; Zhang, Y.; Zhu, X., Drying kinetics of rice straw under isothermal and nonisothermal conditions: A comparative study by thermogravimetric analysis. Energy \& Fuels 2012, 26, (7), 4189-4194.

15. Jamaleddine, T. J.; Ray, M. B., Application of computational fluid dynamics for simulation of drying processes: A review. Drying Technology 2010, 28, (2), 120-154.

16. Kucuk, H.; Midilli, A.; Kilic, A.; Dincer, I., A review on thin-layer drying-curve equations. Drying Technology 2014, 32, (7), 757-773.

17. Chen, D.; Zheng, Y.; Zhu, X., In-depth investigation on the pyrolysis kinetics of 
raw biomass. Part I: kinetic analysis for the drying and devolatilization stages. Bioresource Technology 2013, 131, 40-46.

18. Cai, J.; Chen, S., Determination of drying kinetics for biomass by thermogravimetric analysis under nonisothermal condition. Drying Technology 2008, 26, (12), 1464-1468.

19. Joardder, M. U.; Karim, A.; Kumar, C.; Brown, R. J., Determination of effective moisture diffusivity of banana using Thermogravimetric analysis. Procedia Engineering 2014, 90, 538-543.

20. Erbay, Z.; Icier, F., A review of thin layer drying of foods: Theory, modeling, and experimental results. Critical Reviews in Food Science and Nutrition 2010, 50, (5), 441464.

21. Vega-Gálvez, A.; Lara, E.; Flores, V.; Di Scala, K.; Lemus-Mondaca, R., Effect of selected pretreatments on convective drying process of blueberries (var. O'Neil). Food and Bioprocess Technology 2012, 5, (7), 2797-2804.

22. Demirbas, A., Effect of initial moisture content on the yields of oily products from pyrolysis of biomass. Journal of Analytical and Applied Pyrolysis 2004, 71, (2), 803815.

23. Reddy, P. J., Municipal Solid Waste Management: Processing - Energy Recovery Global Examples. Book Syndicate: 2011.

24. Baker, C. G. J.; Baker, C., Industrial Drying of Foods. Springer: 1997.

25. Mujumdar, A. S., Handbook of Industrial Drying, Fourth Edition. Taylor \& Francis: 2014. 